\title{
Editorial
}

\section{Florian Gebhard}

Published online: 25 April 2013

(C) EFORT 2013

\section{Dear Colleagues,}

Within Europe the care of traumatised patients is taken over by different surgical disciplines.

In German-speaking countries, there is a special type of "trauma surgeon" who had training in general surgery and is dealing with musculoskeletal trauma.

The name "trauma surgery" in other countries is dedicated to surgeons that take care of major traumas and are usually trained in general surgery.

In other countries, orthopaedic surgeons take care of trauma.

In summary, trauma care is addressed in many ways, and is a very important topic within Europe that has been addressed by the WHO Bone and Joint Decade over the last 10 years.
The better the care of the traumatized patient, the better will be the outcome.

In all European countries, we are facing an increasing number of traumatized patients in the older population.

As a result of an increased number of joint replacements, we can see a parallel increasing number of fractures associated with joint replacement.

Within the EFORT Trauma Taskforce, we developed an EFORT EXMEX Format which covers the challenges of periprosthetic fracture treatment.

The current issue provides an up to date overview about the issue of periprosthetic fracture treatment.

Each article is written by a team of well-known authors.

With this issue of EOTR, we would like to give the word "trauma" a new format and importance within the EFORT.

F. Gebhard $(\bowtie)$

Department for Orthopaedic Trauma, Hand- and Reconstructive

Surgery, Ulm University, Center for Surgery,

Albert Einstein Allee 23, 89081 Ulm Germany

e-mail: Florian.Gebhard@uniklinik-ulm.de 